\title{
Taiwanese EFL Learners’ English Relative Clauses Learning
}

\author{
Ching-Ying $\operatorname{Lin}^{1} \&$ Shu-Yuan Chuang ${ }^{2}$ \\ ${ }^{1}$ Department of Applied English, National Pingtung University, Taiwan \\ ${ }^{2}$ Cho-Shan Elementary School, Taiwan \\ Correspondence: Ching-Ying Lin, Department of Applied English, National Pingtung University, Taiwan \\ E-mail: chingyinglin6@gmail.com
}

Received: March 21, 2014 Accepted: April 25, 2014 Online Published: July 30, 2014

doi: 10.5539/ijel.v4n4p99 URL: http://dx.doi.org/10.5539/ijel.v4n4p99

\begin{abstract}
Relative clause processing in Chinese is different from English. However, Chinese EFL learners face difficulty when they produce relative clauses. In order to help EFL learners be familiar with their writing skills and ease their anxiety, making a clear concept is necessary. Therefore, contrastive analysis (CA), a rule of a comparison between Chinese and English relative clauses is employed in this study. In the experiment, the treatment group had a positive evaluation of the contrastive analysis approach. Students felt that CA approach could really help them learn English clauses. They were willing to apply the method in the learning procedure. In addition, EFL learners also suggested that EFL teachers need to provide more illustrations and interpretations about the CA approach in the learning process.
\end{abstract}

Keywords: contrastive analysis, relative clauses, error types

\section{Introduction}

Relative clause processing in Chinese is different from English. This leads Chinese EFL learners to face difficulties in comprehending relative clauses as the sentence structure differs in regard to the modification position in English, and confusion while writing or speaking. In Taiwan junior high schools, relative clause teaching without a specific comparison is ambiguous for learners. The researcher observes that few relative clauses are applied in EFL learners' writing production. Therefore, providing a solid notion for learners to elevate their writing skills is essential. Basically, achieving students' concise writing production is imperative.

As for the error types in producing English relative clauses, a systematic classification may give learners and instructors resources for improvement of learning and teaching aspects. Normally, when students are confused by relative pronouns, there are two reactions: one is avoiding English relative clauses output, and the other is generating incorrect relative clauses. Gathering and generalizing their error types can not only help teachers to provide prompt effective teaching of relative clauses, but allow teachers to further refine their course.

\subsection{Problem Statement}

Relative clause processing in Chinese was different from English. This led Chinese EFL learners to present difficulties while comprehending relative clauses which sentence structure differs in modification position in English. It also caused problems for EFL learners like Chinese confused while writing or speaking. In Taiwan junior high schools, relative clauses teaching without a specific comparison might remain ambiguous for learners. The researcher observed that there were few relative clauses to be applied in EFL learners' communication. As a result, providing a solid notion for learners to elevate their writing skills was essential.

\subsection{Purpose of the Study}

This study is aimed to investigate the perception while Chinese EFL learners processing relative clauses with the use of contrastive analysis instruction. Based on the data gathered from the experiment, the error types of English RC pronoun selection are classified. According to the error types, teachers can make a clear concept for learners when they deal with the difficult syntactic order which is different from Chinese. Moreover, EFL learners' aspect on CA, a method for learning RCs smoothly and easily is focused on the study.

\subsection{Research Questions}

1) What are the error types of English relative clauses that EFL learners are producing? 
2) What are EFL learners' perceptions concerning CA instruction?

\section{Literature Review}

\subsection{Contrastive Analysis Instruction in Second Language Learning}

Marton (1973) mentioned that contrastive analysis has advantages when applied to teaching and learning a second language. Lambert et al. (1967) carried out an experimental study and found that ESL learners' courses with a direct method that separated native and second language, performed less well than those instructed in an interactively with semantic features of both languages. However, in Marton's (1973) study, objections from some scholars argued that in order to master the second language, it would be better not to process both languages at the same time (Marton, 1973), since the interference resulting from referring to both languages might cause interruptions. They suggested that instructors and learners should follow a procedure whereby first and second language learning proceed individually, thereby precluding such interference.

Marton (1973) stated that learners' mother tongue had great influence in a second language learning course, especially where the second language was regarded as a foreign language, with learners acquiring the second language in schools without being entirely immersed in an intensive course or in a country where the second language was spoken. In such circumstance, it was a hard task for EFL learners to acquire the foreign language. Even when learners were exposed to a whole language environment, they did not necessarily acquire the target language automatically, especially for adult learners (Marton, 1973). Take Taiwan's learning phenomenon for an example: English is treated as a foreign language. EFL learners need to memorize diverse features of the target language. Hence, using the assistance of native language to assist in clarifying the similarity and difference between the two languages might be feasible.

Actually, in the fifties and sixties, CA applied in teaching a second language was not acceptable in North America because it was thought that the similarity to structure method which CA was as a compensation material for the lack of native language. Objectors, such as Dulay, Burt and Krashen (1982) stressed rejection of CA input in teaching and demonstrated that TPR in teaching performed better than CA did. However, Ronald (1996) confirmed in his research the effectiveness of exploiting CA to elevate adult learners' English ability. He argued that the supporting research claimed by Dulay, Burt and Krashen (1982) with regard to the validity of TPR in language teaching being superior to CA was not only a short term effect but also the result of a defect in research design.

Furthermore, Von Elek and Oscarsson (1973) stated that the best foreign language teaching was employing CA instruction, with the assistance of native language and grammatical explanation. The criticism of CA as an instrument for error prediction further impaired the value of CA. The objectors, such as Dulay, Burt, and Krashen (1982) inferred in their studies that there was a little advantage of administrating error analysis which exploited the concept of negative transfer in second language learning. They held that native language interference constituted nothing but a tiny proportion which caused errors in output. Therefore, CA was regarded as being irrelevant to second language acquisition in North America at that time. Nevertheless, there were contemporary supporters in Europe who identified the advantages of CA: the use of CA can provide second language learners with explanations to help them understand the differences between the target language and mother tongue. Even though Dulay, Burt and Krashen (1982) neglected the importance of CA in language teaching, undeniably, the issue of negative transfer was noticed and interested by researchers was renewed.

\subsection{Error Types in English Relative Clauses}

As Chen (2004) stated, by means of error analysis, EFL learners' language ability within an inter-language process can be observed. The error evidence signifies the EFL learners' developmental process. To estimate the degree of interference between the native and target languages, error analysis is a supplement for contrastive analysis. According to Corder (1967), errors reflect EFL learners' cognitive knowledge in regard to the rules of a target language. Besides, Burt and Kiparsky (1972) pointed out three major reasons for the errors: transfer, development and performance factors. To illustrate the factors systematically, three sections of the causes are shown as follows.

\subsubsection{Transfer}

Transfer is the learning process whereby language learners apply their native language knowledge to the target language (Richards, 1973) by two types of transfer: negative and positive transfer. As Richards et al. (1998) mentioned, negative transfer comprises an error whereby the native language's pattern or rules are applied in the target language in a learning process. For example, EFL learners might produce a sentence like There have a lot of people in the park rather than There are a lot of people in the park, due to the transfer of the Chinese pattern; 
on the other hand, a positive transfer smoothens the process. It results from the learners' native language and the target language sharing a common structure. The learners' native language is copied / transposed to the target language due to the similarity of the two languages.

\section{Methodology}

\subsection{Research Design}

The research aimed to define the perception of Chinese EFL learners towards contrastive analysis teaching (CAT) in learning English relative clauses. Besides, learners' production of English relative clauses is classified to different error types. In the chapter, the first part is a description of participants. Next, instruments are carried out the study. Then, the procedure of data collection and implementation of the study were operated. A discussion of analysis of data is placed in the end.

\subsection{Subjects}

The total 60 samples were in the ninth grade and they were native Chinese speakers. Based on the background, participants received the same education scheme. In view of educate policy, participants focused on the grammar and sentence structures as basic competence. Consequently, all participants were assumed to be equipped with the basic grammar notion. Since the subjects had been divided into two different classes after the participants registered at the school, the division of controlled group and treatment group followed the original separation. Before the experiment, a preliminary test was operated in week one to confirm that all the participants were at the proper stage in relative clause acquisition. Additionally, the target structures of relative clauses were unknown to the participants. During the experiment, the controlled group processed usual instructions in English relative clauses without contrastive analysis of relative clause and the other was a treatment group immersed in a procedure which applied the contrastive analysis teaching. To be more specifically, the controlled group was guided conventional method which simply provided rules of RCs and then the participants in control group were asked to produce their acquisition. Rather, the treatment group was supplied with a contrastive analysis in English and Chinese of RCs. Performing an obtainment was followed. The samples were carried out a task at the end of experiment in which two groups were required to produce a sentence combination practice and a translation test in English relative clauses. At last, the researcher assigned the participants in treatment group questionnaire to gather their viewpoints about CA.

\subsection{Instruments}

In order to process the research, there were two instruments for collecting data. A task comprised two tests and an interview about the two groups' perception on CA. The former was conducted to gather data in light of analysis was a task in which participants' relative clauses volumes and correct rates were measuring after a treatment experiment lasted four weeks. The task comprised two tests were individually a combination exercise and a translation practice. The first combination exercise contained fifteen questions which were designed to require the participants linking two sentences with a proper relative pronoun. The two tests aimed to glean materials by way of grasping participants' RCs acquisition in distinct instructions in order to classify the error types. The latter, an interview would be proceeding at the end of the experiment in order to get learners' perception towards contrastive analysis instruction.

\subsection{Procedure}

Two groups were instructed by the researcher in different teaching methods related to RCs for forty minutes each class. A task was administrated at the end of the experiment and then an interview with participants followed. The test and an interview lasted for forty minutes individually after the presentation for teaching RCs. The two groups were arranged two tests within the task in which participants were required to generate sentence combination and a translation.

Individual group was taught by the researcher with different methods to learn English relative clauses. In controlled group class, participants learned from the function of respectively relative pronoun and the steps united two simple sentences to a relative clause with a proper relative pronoun. There were five examples for explaining the uses of various relative pronouns representing for antecedents in different position, such as who, which, whom and whose. The treatment group was provided the same material and procedure as the controlled group. However, there was an additional contrastive analysis between English and Chinese relative clauses. The researcher explained the differences of relative pronouns and their positions between English and Chinese. For example, in English relative clauses, relative pronouns were decided according to the antecedents' function rather displayed a Chinese character " $d e$. . Besides, positions of relative pronouns and relative clauses in English and Chinese were illustrated by a comparison table designed by the researcher. 
As the presentation accomplished by the researcher, two groups were supplied same materials which were aimed to assess the affection in two different teaching methods. Fifteen sentence combination which was designed to follow a sequence which within five parts. Each part comprised three questions. According to the direction from the top of the test paper, participants were required to complete the practice within fifteen minutes. A translation comprised five Chinese relative clauses. In the end, subjects were interviewed by the researcher in order to gather aspects on part of CA.

\subsection{Data Analysis}

In order to carry out the data analysis, the study comprised both quantitative and qualitative methods. In terms of EFL learners' perceptions on CAT, the data were analyzed by way of descriptive statistics. SPSS (Statistical Package for Social Science) windows 12.0 was administered to analyze all data of quantitative analysis. The statistical significance level for the $t$-test was set at .05 .

\section{Findings and Discussions}

\subsection{Research Question One}

What are the error types of English relative clauses that EFL learners are producing?

According to Chen (2004), seven error types were found in EFL learners' RCs production (see Table 1).

Table 1. Error types categorization

\begin{tabular}{cl}
\hline Error Types & \\
\hline Type 1 & Relative pronouns incorrect choice \\
Type 2 & Incorrect omission of a preposition before or after a RC \\
Type 3 & Relative pronouns incorrect omission \\
Type 4 & Improper use of quantity in RCs \\
Type 5 & Redundant use of pronouns \\
Type 6 & Non-restrictive RCs and restrictive RCs' confusion \\
Type 7 & Relative pronoun and the following verb inharmonious \\
\hline
\end{tabular}

Based the corpus collected from the participants' production of relative clauses, containing sentence combination and Chinese-English translation, the researcher investigated the error types that EFL learners committed, and described the results in Table 2. Concerning the proficiency of the participants, two tasks were designed in accordance with level of ninth graders in junior high school. On one hand, the control group, the estimation of error types includes: type 1 (relative pronouns incorrect choice) with 23\%, type 3 (relative pronouns incorrect omission) with $18 \%$, type 5 (redundant use of pronouns) $26 \%$ and type 7 (relative pronoun and the following verb inharmonious) with $17 \%$. On the other hand, error type 1 performed in experimental group with $21 \%$, type 3 with $12 \%$, type 5 with $16 \%$ and type 7 with $14 \%$.

Table 2. Percentages of errors in RCs production by the control and experiment groups $(n=60)$

\begin{tabular}{lcc}
\hline \multicolumn{1}{c}{ Error types } & $\begin{array}{c}\text { Control } \\
\text { Group }\end{array}$ & Experiment Group \\
\hline Redundant use of pronouns & $26 \%$ & $16 \%$ \\
Relative pronouns incorrect omission & $18 \%$ & $12 \%$ \\
Relative pronouns incorrect choice & $23 \%$ & $21 \%$ \\
Relative pronoun and the following verb inharmonious & $17 \%$ & $14 \%$ \\
\hline
\end{tabular}

\subsection{Research Question Two}

What are EFL learners' perceptions concerning CA instruction?

Based the open-ended questionnaires, the results of students' perception regarding the contrastive analysis 
approach after they were notified (CG) and instructed (EG) are revealed in Table 3.

Table 3. Participants' perceptions regarding the contrastive analysis approach $(n=60)$

\begin{tabular}{cc}
\hline Item \\
\hline 1 I'd use contrastive analysis approach to learn Englis \\
sentence writing. \\
2 I like to apply contrastive analysis to learn about \\
relative clauses. \\
Learning English sentence writing by means of \\
contrastive analysis is more comprehensible than \\
learning by means of the traditional approach.
\end{tabular}

4 It is fun to learn English sentence writing by way of contrastive analysis.

5

I can learn writing complete syntactic sentences quickly by the contrastive analysis approach.

I can produce complex sentences in my writing, such 6 as those with relative clauses, by the contrastive analysis approach.

7

I can review sentence patterns by using contrastive analysis.

8

I know sentence pattern, such as relative clauses, by using contrastive analysis.

I need to know relative clauses in sentence patterns in 9 my native language prior to examining English sentence patterns.

10

I want to do better when I apply contrastive analysis to my writing.

I think producing more relative clauses by way of

11 contrastive analysis instead of the traditional method in my text can bring a sense of achievement.

12

I will actively use contrastive analysis to check my writing.

13 I think the teacher's explanation before using "contrastive analysis" can help me learn about relative clauses more efficiently.

14 I think peers' discussion during the contrastive

\begin{tabular}{|c|c|c|}
\hline Group & Mean & SD \\
\hline Control & 2.43 & .57 \\
\hline Experimental & 2.60 & .62 \\
\hline Control & 1.30 & 1.47 \\
\hline Experimental & 1.43 & .50 \\
\hline Control & 1.17 & .38 \\
\hline Experimental & 1.37 & .56 \\
\hline Control & 1.17 & .38 \\
\hline Experimental & 1.33 & .61 \\
\hline Control & 1.40 & .86 \\
\hline Experimental & 1.60 & .81 \\
\hline Control & 1.43 & .68 \\
\hline Experimental & 1.60 & .67 \\
\hline Control & 1.43 & .57 \\
\hline Experimental & 1.63 & .81 \\
\hline Control & 1.97 & 1.00 \\
\hline Experimental & 2.03 & .93 \\
\hline Control & 1.83 & .79 \\
\hline Experimental & 2.03 & 1.03 \\
\hline Control & 1.83 & .95 \\
\hline Experimental & 2.20 & 1.03 \\
\hline Control & 1.47 & .57 \\
\hline Experimental & 1.67 & .88 \\
\hline Control & 1.43 & .73 \\
\hline Experimental & 1.77 & .78 \\
\hline Control & 1.40 & .50 \\
\hline Experimental & 2.59 & 1.38 \\
\hline Control & 1.27 & .52 \\
\hline
\end{tabular}


analysis instruction can help me improve my sentence writing.

15

Contrastive analysis helps me perceive the function of relative pronouns.

The contrastive analysis can help me to construct

16 sentences from simple to difficult (e.g. from simple sentences to compound, complex sentence)

The sentence length that I used was less than 5 words

17 before I learned about relative clauses by contrastive analysis.

I can make sentence with length longer than 5 words

18 after learning about relative clauses by contrastive analysis.

I like to use contrastive analysis to learn about relative clauses.

I am more interested in English sentence writing after 20 using contrastive analysis to learn about relative clauses.

21

I find it useful to write a paragraph by contrastive analysis before starting to write in English.

By focusing my attention on contrastive analysis, my writing improves.

23

Studying grammar in contrastive analysis is an effective way to improve my writing.

24

I improved my writing skills by working on grammatical errors.

25 I retrieve useful information by contrastive analysis.

26 Learning about English relative clauses by contrastive analysis approach is easier than a direct method.

27

To help my English writing ability, I memorize English sentence patterns.

Before I can master English relative clauses, I have to be familiar with Chinese sentence patterns. After contrastive analysis demonstration, relative
Experimental

1.20

.48

Control

$1.13 \quad .35$

Experimental

1.23

Control

1.13

.35

Experimental

1.20

.43

Control

1.53

.62

Experimental

2.30

1.06

Control

1.40

.62

Experimental

1.50

.68

Control

1.60

.67

Experimental

$1.70 \quad .92$

Control

1.80

.92

Experimental

$1.93 \quad .83$

Control

$1.80 \quad .96$

Experimental

$1.87 \quad .73$

Control

$1.17 \quad .38$

Experimental

$1.50 \quad .63$

Control

1.13

.43

Experimental

$1.33 \quad .55$

Control

$1.97 \quad .85$

Experimental

2.37

1.07

Control

2.00

0.95

Experimental

2.23

1.19

Control

$1.87 \quad .86$

Experimental

1.93

.83

Control

1.87

.90

Experimental

$1.77 \quad .90$

Control

$1.87 \quad .82$

Experimental

$1.87 \quad .73$

Control

1.93

1.78 


\begin{tabular}{cccc}
\hline clauses can be better understood. & Experimental & 1.77 & .82 \\
$30 \quad \begin{array}{c}\text { Contrastive analysis allows EFL learners to } \\
\text { efficiently use their time for English writing, and } \\
\text { increases the speed of writing. }\end{array}$ & Control & .57 & .10 \\
\hline
\end{tabular}

\section{Conclusion and Suggestions}

The results of error types in EFL learners' RC production showed that "Redundant use of pronouns" was at the highest level. For EFL learners, the syntactic order of English relative clauses was difficult, and they interpreted English relative clauses on their experience in learning Chinese. It caused pronouns in a relative clause to be used redundantly. The second type which EFL learners committed was "Relative pronouns incorrect omission". When the relative clauses modified an indefinite noun, EFL learners often omitted the relative pronoun. The third and fourth types were individually "Relative pronouns incorrect choice" and "Relative pronoun and the following verb being inharmonious". Mostly, EFL learners who made such mistakes were careless. Moreover, they did not pay attention to what the antecedent was. On the basis of the error types, instructors put their focus on the errors and helped learners to produce correct writing.

Students in the experimental group supported that the CA approach had a significant effect. Indeed, by way of a clear contrastive analysis between two languages, especially different syntactic order, EFL learners would perceive and easily distinguish the characteristic. According to the questionnaires, the experimental group expressed that they would use the contrastive analysis approach to learn English sentence writing. Besides, they indicated that the teachers' explanation before they were instructed about the approach was helpful for their learning about English relative clauses. As for the control group's perception, they thought that improving their writing skill by working on grammatical errors would be useful.

\subsection{Discussion on Significant Findings}

The error types were based on the material that EFL learners produced in their two writing tasks. Most EFL learners made the most mistakes in regard to the redundant use of pronouns, resulting in Chinese relative clauses allowing a pronoun to be in a relative clause rather in English relative clauses. Besides, the wrong omission of relative pronouns also resulted to EFL learners using Chinese sentence patterns for English relative clauses, thereby producing Chinese-like sentences. It was necessary for learners to notice the difference between the two languages' syntactic structures.

In the last part of the experiment, the treatment group had a positive evaluation of the contrastive analysis approach, feeling that it could really help them learn English clauses. They were willing to apply the method to their learning procedure; however, the complex concept of English relative clauses was not easily acquired. EFL learners suggested that teachers provide more illustrations and interpretations about the CA approach. Based on the suggestions, instructors might be more concerned about helping to ease the perplexity of students with the CA approach.

\section{References}

Chen, C.-S. (2004). A Study on Errors in English Relative Clauses Made By Senior High School Students in Taiwan. (Unpublished master's thesis). National Kaohsiung Normal University, Kaohsiung, Taiwan. Retrieved from http://www.airitilibrary.com/Publication/alDetailedMesh?docid=U0024-2301200813432282

Feng, Z. (2011). Researches on contrastive linguistics in the second language teaching in the west and china. Sino-US English Teaching, 8(3). Retrieved from http://www.cqvip.com/QK/88585X/201103/37653190.html

Fries, C. (1945). Teaching and learning English as a foreign language. Ann Arbor, MI: University of Michigan Press.

Ghabanchi, Z., \& Vosooghi, M. (2006). The role of explicit contrastive instruction in learning difficult 12 grammatical forms: a cross-linguistic approach to language awareness. An International Online Journal. 6(2). Retrieved from http://www.readingmatrix.com/articles/ghabanchi-vosooghi/article.pdf

Huang, L. (2001). The potential influence of 11 (Chinese) on 12 (English) communication. ELT, 64(2). http://dx.doi.org/10.1093/elt/ccp039

Jin, X., \& Qiao, M. (2010). Interlingual factories Chinese college students' acquisition of English relative clauses. Chinese Journal of Applied Linguistics, 33(1). 110-126. Retrieved from 
http://connection.ebscohost.com/c/articles/57233893/interlingual-factors-chinese-college-students-acquisiti on-english-relative-clauses

Karshen, S. D. (1982). Principles and practice in second language acquisition. New York, NY: Pergamon.

Lado, R. (1957). Linguistics across culture. Ann Arbor, MI: University of Michigan Press.

Lambert, W. E. (1967). Psychological approaches to the study of language. Foreign language teaching, 215-250. http://dx.doi.org/10.1111/j.1540-4781.1963.tb06208.x

Laufer, B., \& Girsai, N. (2008). Form-focused instruction in second language vocabulary learning: A case for contrastive analysis and translation. Applied Linguistics. 29(4), 694-716. http://dx.doi.org/10.1093/applin/amn018

Li, Y. (2003). Effects of the "Focus on Form" Approach on EFL Learning in An Immersion Program in Taiwan. (Unpublished master's thesis). National Tsing Hua University, Hsinchu, Taiwan. Retrieved from http://ir.lib.nthu.edu.tw/handle/987654321/34319

Natalie, C., Hermon, G., \& Zukouski, A. (2009). Young children's production of head-final relative clauses: Elicited production data from Chinese children. $J$ East Asian Linguist, 18(4), 323-360. http://dx.doi.org/10.1007/s10831-009-9047-y

$\mathrm{Pu}, \mathrm{M}$. (2007). The distribution of relative clauses in Chinese discourse. Discourse Processes, 43(1). http://dx.doi.org/25-53. 10.1207/s15326950dp4301_2

Ronald, S. (1996). The advantage of exploiting contrastive analysis in teaching and learning a foreign language. International Review of Applied Linguistics in Language Teaching, 34(3), 192-201, http://dx.doi.org/10.1515/iral.1996.34.3.183

Ronald, S. (1996). The advantage of exploiting contrastive analysis in teaching and learning a foreign language. International Review of Applied Linguistics in Language Teaching, 34(3). http://dx.doi.org/10.1515/iral.1996.34.3.183

\section{Copyrights}

Copyright for this article is retained by the author(s), with first publication rights granted to the journal.

This is an open-access article distributed under the terms and conditions of the Creative Commons Attribution license (http://creativecommons.org/licenses/by/3.0/). 